\title{
Time of appearance of ossification centers in carpal bones
}

\author{
A radiological retrospective study on Saudi children
}

\author{
Khulood M. Al-Khater, MSc, PhD, Tarek M. Hegazi, MBBS, FRCPC, Hanadi F. Al-Thani, MBBS, SEAP, \\ Haider T. Al-Muhanna, MBBS, Bayader W. Al-Hamad, MBBS, Salwa M. Alhuraysi, MBBS, Walaa A. Alsfyani, MBBS, \\ Fadk W. Alessa, MBBS, Areeg O. Al-Qwairi, MBBS, Asma O. Al-Qwairi, MBBS, Sujatha B. Bayer, MD, Faiza B. Siddiqui MD.
}

\begin{abstract}

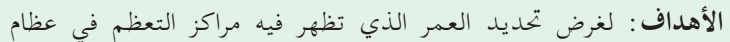

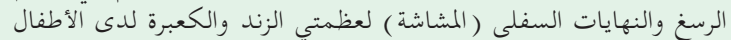

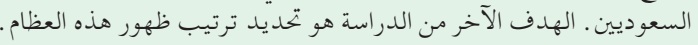

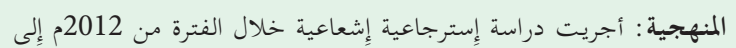

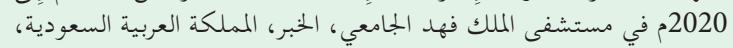

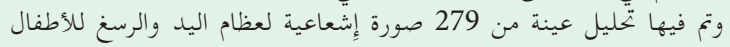
السعوديين.

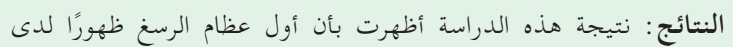

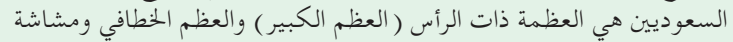

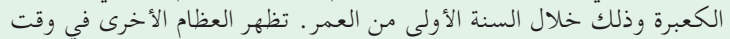

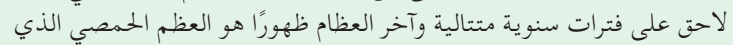
يظهر في نهاية العقد الأول من العمر.

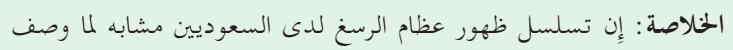

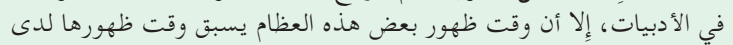

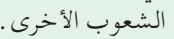

Objectives: To find reference data for the time of appearance of ossification centers in carpal bones and the lower ends of the radius and ulna in the Saudi population. In addition, to check the sequence of appearance of carpal bones and the relation of this sequence to the appearance of distal epiphyses of the radius and ulna.

Methods: A retrospective radiological study was carried out between 2012 to 2020 at King Fahad Hospital of the University, Al-Khobar, Saudi Arabia. A sample of 279 hand/wrist plain radiographs of Saudi children was analyzed.

Results: The first bones at the wrist region to appear in Saudi children are the capitate, hamate, and distal epiphysis of the radius, and these appear during the first year of life. The other bones develop subsequently at yearly intervals, and the last one to appear is the pisiform, which arises at the end of the first decade of life.
Conclusion: The sequence of appearance of carpal bones in the Saudi population is similar to what is described in the literature. However, the time of appearance of some of these bones is earlier than that in other populations.

Keywords: carpal bones, Saudi children, x-ray, ossification, radiology, radius, ulna

Saudi Med J 2020; Vol. 41 (9): 938-946 doi: 10.15537/smj.2020.9.25348

From the Department of Anatomy (Al-Khater); from the Department of Radiology (Hegazi, Al-Thani, Al-Muhanna); and from the College of Medicine (Al-Hamad, Alhuraysi, Alsfyani, Alessa, Al-Qwairi), Imam Abdulrahman Bin Faisal University, Dammam, Kingdom of Saudi Arabia.

Received 7th June 2020. Accepted 19th August 2020.

Address correspondence and reprint request to: Dr. Khulood $M$. Al-Khater, Department of Anatomy, College of Medicine, Imam Abdulrahman Bin Faisal University, Dammam, Kingdom of Saudi Arabia.E-mail:kalkhater@iau.edu.sa

ORCID ID: https://orcid.org/0000-0003-2600-1741

B one development starts early during the embryonic period, but is only completed around the age of adolescence. ${ }^{1}$ Endochondral ossification is the process by which most bones develop. This type of ossification means that the bone is formed by the deposition of collagen and minerals on a cartilaginous model. ${ }^{1}$ Bones vary in the time of their formation. The first location of bone formation within the background of cartilage is known as the primary ossification center, which usually develops before birth, while the bony spot that appears after birth is known as the secondary ossification center. ${ }^{1}$

Carpal bones are 8 short bones arranged in 2 rows, each with 4 bones in the region of the wrist. From lateral to medial, bones of the proximal row are the scaphoid, 
lunate, triquetral, and pisiform, and those of the distal row are the trapezium, trapezoid, capitate, and hamate. ${ }^{2}$ These bones ossify in cartilage, and the earliest sign of formation of these cartilages in the wrist region of the developing embryo occurs during the second month of intrauterine development. ${ }^{3}$ The cartilage of the capitate is the first to appear and that of the pisiform is the last. As the ossification of these carpal cartilages occurs only after birth, the carpals are still cartilaginous at the time of birth.

Skeletal age reflects the maturity of an individual, and skeletal age assessment is commonly used to judge the actual age of a person. Aside from dental eruption, of particular importance for age determination in young children is the development of wrist bones. ${ }^{4}$ Carpal bones are useful in determining the skeletal age of individuals and assessing their growth status., ${ }^{5,6}$ This is particularly of great importance for pediatricians to diagnose metabolic or endocrine disorders. Medicolegally, it is necessary to estimate the bone age in case no birth certificate has been issued. ${ }^{5,6}$

Standard anatomy literature describes a specific pattern of development of carpal bones. The first bones to ossify are the capitate and hamate, and this occurs during the first year of life. The triquetral is next to appear arising during the third year of life and the lunate appears on the fourth year of life. The scaphoid develops in the fifth year, and the trapezium and trapezoid appear in the sixth year. The last one to appear is the pisiform, which occurs in the twelfth year of life. ${ }^{7}$ Other literature describes a much earlier ossification of pisiform, that is, in the ninth year of life. ${ }^{2}$ In general, the ossification of carpal bones and other bones of the hand occurs earlier in females than in males.

Variations occur among populations with regard to the time of appearance of ossification centers in different bones of the hand and wrist. The literature has documentations for the specific time of appearance of bones for some population types, including American Caucasian, ${ }^{8} \quad$ Indian, ${ }^{9-11} \quad$ Pakistani, ${ }^{12}$ Nigerian, ${ }^{13}$ Sudanese, ${ }^{14}$ and Western Australian. ${ }^{15}$

The present study aims to investigate the time of appearance of carpal bones in both genders of Saudi children, and the time of ossification of distal epiphyses of the radius and ulna. These data will form a reference

Disclosure. Authors have no conflict of interests, and the work was not supported or funded by any drug company. for Saudi children and a basis to diagnose any skeletal and developmental abnormalities.

Methods. Number of online search engines were used by the authors to gather literature for this study, but the main were PubMed, Web of Science, and Summon (the search engine of the digital library at Imam Abdulrahman Bin Faisal University).

This retrospective radiological study was performed on subjects who visited King Fahad Hospital of the University in Al-Khobar, Saudi Arabia during the period between 2012-2020. The study was approved by the Institutional Review Board (IRB -UGS-2019-01290), and is in accordance with ethical principles stated in the Declaration of Helsinki. ${ }^{16}$

The present work included 279 anteroposterior plain $\mathrm{x}$-rays of the wrist or hand that fulfilled the following criteria. Inclusion criteria are as follows: Saudi, children (age: newborn to 14.5 years), and the radiological examination is a normal anteroposterior x-ray of the hand and wrist.

The exclusion criteria are as follows: non-Saudi and the presence of skeletal anomalies (congenital or acquired) or endocrine, metabolic, or nutritional disorders.

Both genders were represented in the sample with an approximate ratio of $1: 1$. The exact numbers are 139 boys and 140 girls. The sample was divided into 15 groups according to age (Table 1). Each age group (except the first one) includes subjects of that specific year \pm 6 months; for example, age group 2 includes subjects as young as 19 months up to 2 years and 6 months. With regard to the first age group (newborn and early infancy), it includes newly born children (0 to 1 month) and children in their early infancy period (2 to 5 months).

The $\mathrm{x}$-ray films were examined digitally by using the database of the Picture Archiving and Communication Systems (PACS). Initially, a random sample of hand $x$-ray films of Saudi children was selected by a radiologist. The original sample had around 400 cases. Six investigators started to examine this random sample in order to select the cases according to the inclusion and exclusion criteria described above. The plan was to collect more cases from the earlier years of childhood ( 0 to 7 years/phase I), than from the later years (8 to 14.5 years/phase II), because carpal bones are expected to start ossification during this earlier time. For each case, a form especially prepared for this study, was filled out. The form has a section that shows the demographic data of the child (namely, the gender, medical record number, date of birth, date of radiological examination, age at time of examination, 
Table 1 - Number of cases in each age group in both genders (N=279).

\begin{tabular}{lccrr}
\hline Age group & $\begin{array}{c}\text { Age limits } \\
\text { (years) }\end{array}$ & $\begin{array}{c}\text { Age limits } \\
\text { (months) }\end{array}$ & \multicolumn{2}{c}{ Number of cases } \\
Male & Female \\
\hline Phase I & & & & \\
$\quad$ Newborn \& early infancy & $<0.5$ & birth-5 & 3 & 4 \\
1 year & $0.5-1.5$ & $6-18$ & 22 & 19 \\
2 years & $1.5-2.5$ & $19-30$ & 12 & 11 \\
3 years & $2.5-3.5$ & $31-42$ & 8 & 22 \\
4 years & $3.5-4.5$ & $43-54$ & 12 & 16 \\
5 years & $4.5-5.5$ & $55-66$ & 13 & 8 \\
6 years & $5.5-6.5$ & $67-78$ & 9 & 16 \\
7 years & $6.5-7.5$ & $79-90$ & 17 & 8 \\
Phase II & & & & \\
8 years & $7.5-8.5$ & $91-102$ & 6 & 6 \\
9 years & $8.5-9.5$ & $103-114$ & 11 & 9 \\
10 years & $9.5-10.5$ & $115-126$ & 8 & 4 \\
11 years & $10.5-11.5$ & $127-138$ & 8 & 7 \\
12 years & $11.5-12.5$ & $139-150$ & 3 & 3 \\
13 years & $12.5-13.5$ & $151-162$ & 3 & 3 \\
14 years & $13.5-14.5$ & $163-174$ & 4 & 4 \\
Total & & & 139 & 140 \\
\hline
\end{tabular}

and reason for the radiological examination). These data were collected from the patients' records that investigators had ethical access to based on the IRB approval. The form has a table with the names of all 8 carpal bones, in addition to the distal epiphyses of the radius and ulna. The investigators recorded whether each of these bones is present. Ossification centers are identified as areas of radio-opacity within radiolucent cartilages. Next, all cases were checked by 2 radiologists to confirm the observations from the other investigators. The radiologists recorded their observations in the same form and only their results were considered in this study. In case of disagreement between the 2 radiologists, a third radiologist was consulted and his opinion was considered.

All collected data from 279 cases were organized in 2 master Excel sheets, one for each gender. Tables for the final analysis of the cases were prepared to summarize the data collected in the study as follows: i) a table presents the age groups with the number of cases in each group of each gender; ii) a table that summarizes the findings related to each of the 10 bones $(8$ carpals and 2 epiphyses) in each gender according to the earliest time of appearance and the age groups at which $\geq 50 \%$ or $100 \%$ of cases show ossification; and iii) a table that shows the percentage of presence of each of the 10 bones in each age group in each gender. At the end, the sequence of appearance of the 8 carpal bones (first to last) was observed.
Statistical analysis. To test whether ossification time in males differs from that in the females, the statistical analysis was performed by the Statistic Package for Social Sciences, Windows, version 21 (IBM Corp, Armonk, NY, USA). Statistical significance was accepted at a level of $p<0.05$.

Results. Age groups, number of cases and gender. The total number of cases examined in this study was 279 with an approximate male-to-female ratio of 1:1. Table 1 shows the number of cases in each age group for each gender. Approximately $74 \%$ of the female cases and $69 \%$ of the male cases were in the first phase of childhood (first 7 years of life).

Time of appearance of ossification centers. The raw data of all male and female cases were organized in master tables. From these master tables, the time of appearance of the bones was extracted. Figures 1-3 show representative examples of the hand/wrist radiographs from male and female cases in different age groups

Carpal bones. Table 2 presents the percentage of presence of the carpal bones in each age group of both genders. Clearly, no carpal bone is present in the age group of newborn and early infancy (Figures 1A \& 1B). This age group contained children of up to 3 months (for girls) or 4 months (for boys), and up to this age no carpal bone was present.

The capitate and hamate were the first carpal bones to ossify. These bones started ossification, in both 
genders, during age group of one with $100 \%$ of cases showing ossification (Figures 1C \& 1D). The youngest children in this group were approximately 6 months for boys and 8 months for girls, and both showed these 2 bones.

The triquetral likewise started to appear during age group of one but in only one-fifth of the cases. This finding is valid for both genders. Subsequent age groups showed a gradual increase in the percentage of appearance of this bone, which is more pronounced in the girls. At age group 3, approximately $73 \%$ of cases in girls and $50 \%$ of cases in boys have this bone ossified.

Figure 2 shows examples of male and female cases with the presence of triquetral at age groups 2 and 3 for the female, but only at age group 3 for the male. All cases of age group 5 had the triquetral bone ossified in both genders.

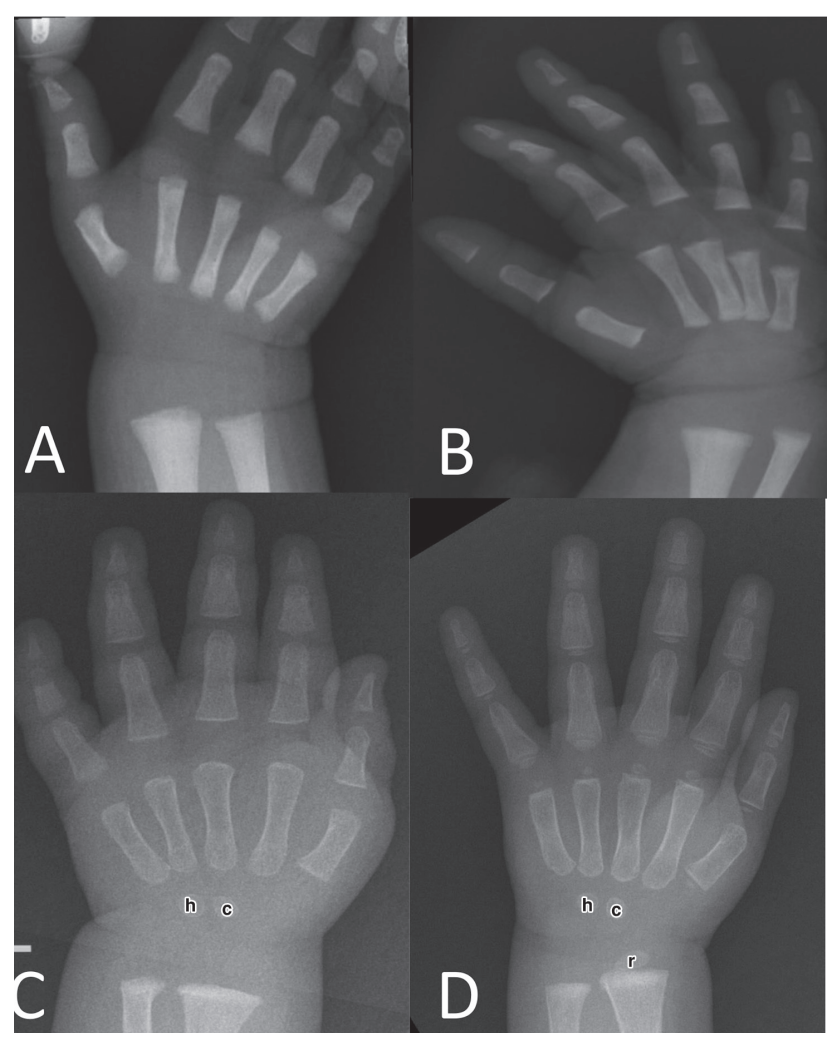

Figure 1 - Hand x-ray of newborns and children of age group one. Plain anteroposterior $\mathrm{x}$-ray of hand and wrist of $\mathrm{A} \& \mathrm{~B}) 2$ newborns and $C \& D) 2$ children of age group one. A: male- 5 days; B: female- 1 day. No carpal bones or distal epiphyses of radius and ulna are present in these 2 newborns. C: male- 13 months; $\mathrm{D}$ : female- 13 months. Note the capitate (c) and hamate (h) in both radiographs $(\mathrm{C} \& \mathrm{D})$. The distal epiphysis of radius $(\mathrm{r})$ is present in the female radiograph (D).
The lunate started to appear in age group 2, in both genders. However, this bone was more prominent in the girls, in which more than $25 \%$ of the cases have the lunate bone, compared to only around $8 \%$ of the boys. This difference between boys and girls was also obvious in age groups 3, 4, and 5. However, in age group 6, almost no difference between the 2 genders was found because more than $80 \%$ of the cases have the lunate. At age group 7, all cases in both genders showed this bone. Figure 2D shows an example of a female case with lunate at age group 3. Figure 3 shows examples of the presence of this bone in both genders at age groups 6 (Figures 3A \& 3B) and 9 (Figures 3C \& 3D).

The scaphoid bone appeared in age group 3 in only a minority of girls (4.5\%) but not yet in boys. A substantial increase in the presence of this bone occurred

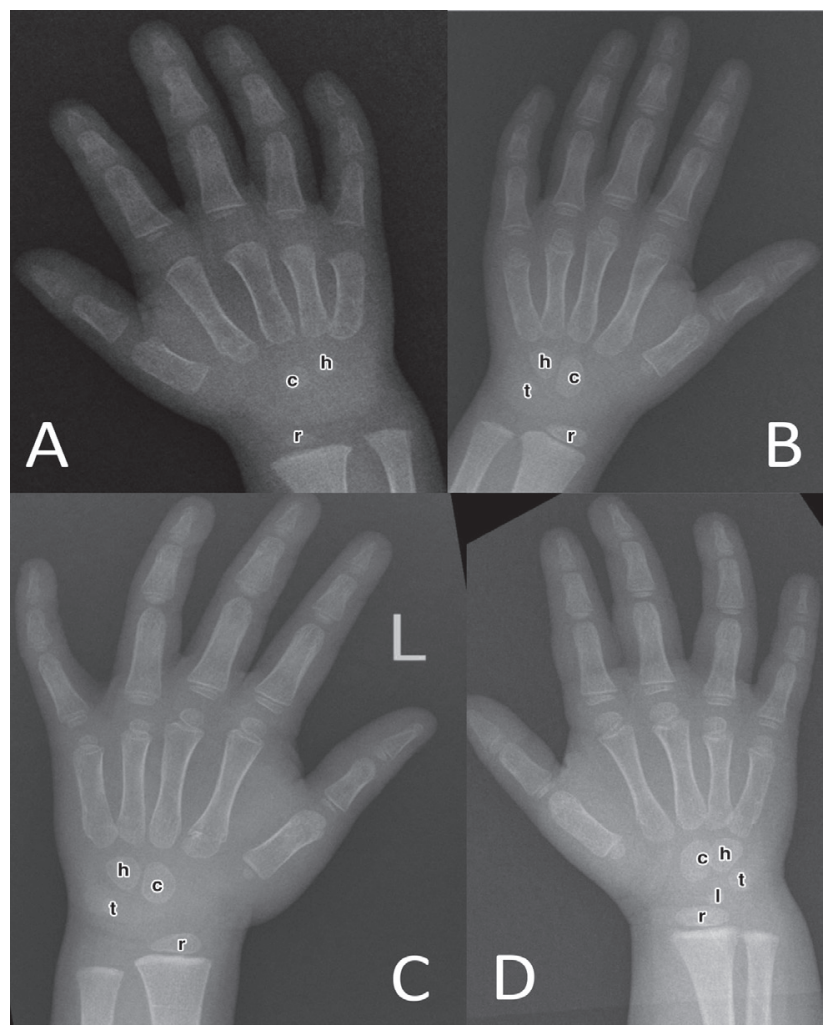

Figure 2 - Hand x-ray of children of age groups 2 and 3. Plain anteroposterior $x$-ray of hand and wrist of 4 children of age groups A\&B) 2 and $C \& D) 3$. A: male- 24 months; B: female24 months. Note the presence of capitate (c), hamate (h) and distal epiphysis of radius $(\mathrm{r})$ in both radiographs $(\mathrm{A} \& \mathrm{~B})$. The female radiograph $(B)$ also has the triquetral $(t)$. C: male- 3 years; D: female- 3 years. Note the presence of capitate (c), hamate $(\mathrm{h})$, triquetral $(\mathrm{t})$ and distal epiphysis of radius $(\mathrm{r})$ in both radiographs $(\mathrm{C} \& \mathrm{D})$. The female radiograph in $(\mathrm{D})$ also has the lunate (l). 


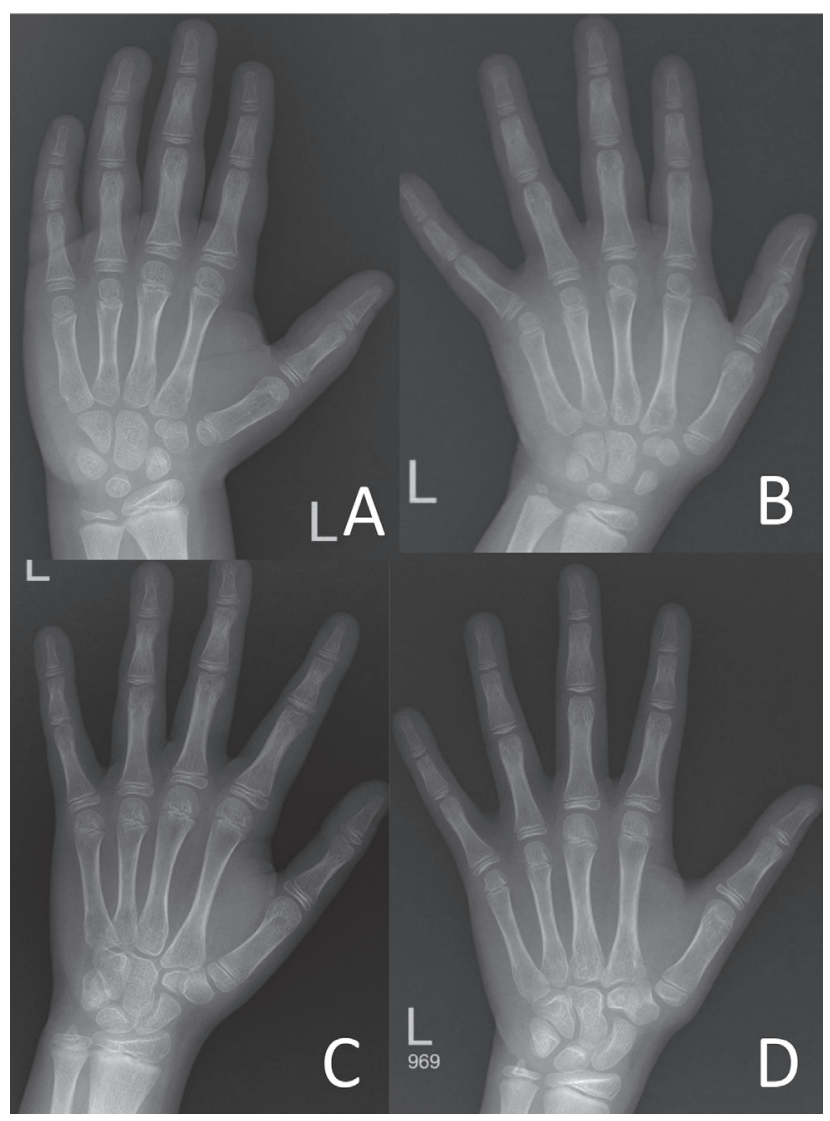

Figure 3 - Hand $x$-ray of children of age groups 6 and 9. Plain anteroposterior $\mathrm{x}$-ray of hand and wrist of 4 children of age groups $A \& B) 6$ and $C \& D) 9$. A: male- 6 years and 5 months; B: female- 6 years and 6 months. Note the presence of all 8 carpal bones (except the pisiform) and the distal epiphyses of radius and ulna in A\&B. C: male- 8 years and 11 months; $\mathrm{D}$ : female- 9 years and 6 months. Note the presence of all 8 carpal bones and the distal epiphyses of radius and ulna in C\&D.

in subsequent age groups of the girls (44\% in age group 4 and $75 \%$ in age groups 5 and 6). All cases of girls showed this bone by age group 7 . In boys, the earliest time of appearance of the scaphoid is in age group 4, with only $8 \%$ of the cases showing this bone. Starting from age group 6 , a clear increase in the appearance of this bone occurred until all cases showed ossification by age group 10. Examples of cases with the ossification of scaphoid in both genders are shown in Figure 3.

The pattern of appearance of trapezium and trapezoid in the girls is almost similar to that of the scaphoid, with the percentage of appearance of these 2 bones at age group 3 higher than that of the scaphoid. In the boys, the pattern of appearance of trapezium is the same as that of scaphoid, but trapezoid appeared at group 5, which is one age group later than for scaphoid and trapezium. The subsequent pattern of appearance of trapezoid is comparable to that of the other 2 bones.

The pisiform is the last to appear in both genders. It started to appear at age group 7 in girls but only at age group 9 in boys, and examples are shown in Figures 3C \& 3D. All cases showed ossification of this bone at age group 10 in girls and 14 years in boys.

Distal epiphyses of radius and ulna. The percentage of appearance of the distal epiphyses of the radius and ulna in all age groups of both genders is presented in Table 2. The distal epiphysis of the radius appeared much earlier than that of the ulna, and this development is valid in both genders. For radius, the distal epiphysis started to appear from age group 1 in boys and girls, but the percentage was higher in girls (Figure 1D). The youngest age at which this bone appeared in girls was 13 months but, surprisingly, 6 months in boys. All female cases showed the distal epiphysis of the radius at age group 3 and male cases at age group 4. Regarding the distal epiphysis of the ulna, it appeared much earlier in girls at age group 3 but only at age group 6 in boys (Figure 3A). The youngest age at which this bone appeared in girls was 2 years and 7 months, but in boys, it was 6 years and 2 months. All female cases showed distal epiphysis of the ulna by 8 years old and male by 10 years old.

Difference in ossification time between male and female cases. Using the Chi-square test, there was a significance association difference between male and female in the pisiform at 95\% ( $p=0.011)$, but all other bones had no significance association at 95\% ( $p>0.05)$. The exact $p$ values for the other bones are as follows: capitate (0.709), hamate (0.709), triquetral (0.557), lunate $(0.164)$, scaphoid $(0.367)$, trapezium $(0.208)$, trapezoid (0.433), radial epiphysis (0.099), and ulnar epiphysis (0.655).

Sequence of appearance of bones. Table 3 shows the time of appearance of bones in the wrist region in both genders. It presents the earliest time of appearance and the time when $\geq 50 \%$ or $100 \%$ of cases showed ossification. From this table, the sequence of appearance of bones is predicted from the earliest time of appearance; if this is the same as the previous bone, then consideration will be given to the times when $\geq 50 \%$ and $100 \%$ of cases showed ossification. Therefore, the sequence is regarded as follows.

Carpal bones. In both genders, capitate and hamate are the first carpal bones to appear, followed by triquetral, and then by lunate. In females, the next development is the concomitant appearance of 3 bones, namely, scaphoid, trapezium and trapezoid. However, in males, scaphoid and trapezium appear together 
Table 2 - Percentage of presence of carpal bones/distal epiphyses (DE) of radius and ulna in each age group (years) of each gender.

\begin{tabular}{|c|c|c|c|c|c|c|c|c|c|c|c|c|c|c|c|c|c|c|c|c|}
\hline \multirow[t]{2}{*}{$\begin{array}{l}\text { Age } \\
\text { group }\end{array}$} & \multicolumn{2}{|c|}{ Capitate } & \multicolumn{2}{|c|}{ Hamate } & \multicolumn{2}{|c|}{ Triquetral } & \multicolumn{2}{|c|}{ Lunate } & \multicolumn{2}{|c|}{ Scaphoid } & \multicolumn{2}{|c|}{ Trapezium } & \multicolumn{2}{|c|}{ Trapezoid } & \multicolumn{2}{|c|}{ Pisiform } & \multicolumn{2}{|c|}{$\begin{array}{l}\mathrm{DE} \text { of } \\
\text { radius }\end{array}$} & \multicolumn{2}{|c|}{$\begin{array}{c}\text { DE of } \\
\text { ulna }\end{array}$} \\
\hline & M & F & M & $\mathrm{F}$ & M & F & M & $\mathrm{F}$ & M & $\mathrm{F}$ & M & $\mathrm{F}$ & M & $\mathrm{F}$ & M & $\mathrm{F}$ & M & $\mathrm{F}$ & M & $\mathrm{F}$ \\
\hline \multicolumn{21}{|l|}{ N \& I } \\
\hline 1 & 100 & 100 & 100 & 100 & 22.7 & 21.1 & & & & & & & & & & & 31.8 & 57.9 & & \\
\hline 2 & 100 & 100 & 100 & 100 & 25 & 36.4 & 8.3 & 27.3 & & & & & & & & & 75.0 & 91 & & \\
\hline 3 & 100 & 100 & 100 & 100 & 50 & 72.7 & & 63.6 & & 4.5 & & 18.2 & & 13.6 & & & 87.5 & 100 & & 9.1 \\
\hline 4 & 100 & 100 & 100 & 100 & 75 & 93.8 & 16.7 & 56.3 & 8.3 & 43.8 & 8.3 & 43.8 & & 37.5 & & & 100 & 100 & & 12.5 \\
\hline 5 & 100 & 100 & 100 & 100 & 100 & 100 & 46.2 & 75 & 7.7 & 75 & 7.7 & 75 & 15.4 & 75 & & & 100 & 100 & & 25.0 \\
\hline 6 & 100 & 100 & 100 & 100 & 88.9 & 100 & 88.9 & 81.3 & 44.4 & 75 & 44.4 & 75 & 55.6 & 62.5 & & & 100 & 100 & 33.3 & 37.5 \\
\hline 7 & 100 & 100 & 100 & 100 & 100 & 100 & 100 & 100 & 94.1 & 100 & 94.1 & 100 & 94.1 & 100 & & 25 & 100 & 100 & 52.9 & 87.5 \\
\hline 8 & 100 & 100 & 100 & 100 & 100 & 100 & 100 & 100 & 83.3 & 100 & 83.3 & 100 & 66.7 & 100 & & 33.3 & 100 & 100 & 66.7 & 100 \\
\hline 9 & 100 & 100 & 100 & 100 & 100 & 100 & 100 & 100 & 81.8 & 100 & 81.8 & 100 & 81.8 & 100 & 18.2 & 66.7 & 100 & 100 & 81.8 & 100 \\
\hline 10 & 100 & 100 & 100 & 100 & 100 & 100 & 100 & 100 & 100 & 100 & 100 & 100 & 100 & 100 & 37.5 & 100 & 100 & 100 & 100 & 100 \\
\hline 11 & 100 & 100 & 100 & 100 & 100 & 100 & 100 & 100 & 100 & 100 & 100 & 100 & 100 & 100 & 25 & 100 & 100 & 100 & 100 & 100 \\
\hline 12 & 100 & 100 & 100 & 100 & 100 & 100 & 100 & 100 & 100 & 100 & 100 & 100 & 100 & 100 & 66.7 & 100 & 100 & 100 & 100 & 100 \\
\hline 13 & 100 & 100 & 100 & 100 & 100 & 100 & 100 & 100 & 100 & 100 & 100 & 100 & 100 & 100 & 66.7 & 100 & 100 & 100 & 100 & 100 \\
\hline 14 & 100 & 100 & 100 & 100 & 100 & 100 & 100 & 100 & 100 & 100 & 100 & 100 & 100 & 100 & 100 & 100 & 100 & 100 & 100 & 100 \\
\hline
\end{tabular}

Values are presented as percentage (\%). M: male, F: female, $\mathrm{N} \& \mathrm{I}$ : newborn and early infancy

Table 3 - Time of appearance of carpal bones and distal epiphyses of radius and ulna in both genders.

\begin{tabular}{|c|c|c|c|c|c|c|}
\hline \multirow[t]{2}{*}{$\begin{array}{l}\text { Region/ name of } \\
\text { the bone }\end{array}$} & \multicolumn{2}{|c|}{$\begin{array}{l}\text { The earliest time of } \\
\text { appearance } \\
\text { (age group) }\end{array}$} & \multicolumn{2}{|c|}{$\begin{array}{c}\text { The age group at which } \\
\geq 50 \% \text { of the cases } \\
\text { showed ossification }\end{array}$} & \multicolumn{2}{|c|}{$\begin{array}{l}\text { The age group at which } \\
100 \% \text { of the cases } \\
\text { showed ossification }\end{array}$} \\
\hline & $\mathrm{F}$ & M & $\mathrm{F}$ & M & $\mathrm{F}$ & M \\
\hline \multicolumn{7}{|l|}{ Carpals } \\
\hline Capitate & 1 & 1 & 1 & 1 & 1 & 1 \\
\hline Hamate & 1 & 1 & 1 & 1 & 1 & 1 \\
\hline Triquetral & 1 & 1 & 3 & 3 & 5 & 5 \\
\hline Lunate & 2 & 2 & 3 & 6 & 7 & 7 \\
\hline Scaphoid & 3 & 4 & 5 & 7 & 7 & 10 \\
\hline Trapezium & 3 & 4 & 5 & 7 & 7 & 10 \\
\hline Trapezoid & 3 & 5 & 5 & 6 & 7 & 10 \\
\hline Pisiform & 7 & 9 & 9 & 12 & 10 & 14 \\
\hline \multicolumn{7}{|l|}{ Distal epiphysis } \\
\hline Radius & 1 & 1 & 1 & 2 & 3 & 4 \\
\hline Ulna & 3 & 6 & 7 & 7 & 8 & 10 \\
\hline \multicolumn{7}{|c|}{ M: male, F: female } \\
\hline
\end{tabular}

followed by trapezoid. The last bone to ossify in both genders is the pisiform.

Distal epiphyses of radius and ulna. The distal epiphysis of radius appears before that of ulna and this order is valid for both genders.

Discussion. The interest in investigating the ossification of carpal bones started a long time ago, from the start of the last century. ${ }^{17}$ Many studies from different populations published data pertaining to time of ossification of carpal bones. The current study is the first to present the time and sequence of appearance of bones in the wrist region of the Saudi population. Knowing this skeletal feature is important for diagnosing developmental abnormalities in Saudi children. Previously, diagnosing such conditions depended on comparison with records of other nations, usually American Caucasian or European. This study can be used as a reference to confirm any suspicious developmental abnormality in Saudi children.

The main finding in this study is that carpal bones start to ossify in the first year of life, starting 
approximately at the age of 6 months. This ossification of carpal bones starts with the capitate and hamate. Following this, other bones appear at variable intervals starting from triquetral followed by lunate, then scaphoid, trapezium and trapezoid (but in males, trapezoid arises after scaphoid and trapezium), and lastly the pisiform. This study shows that the latest time by which all carpal bones are ossified in Saudi females is 10 years, but this time is much later in Saudi males at 14 years. The other finding in this study is related to the time of ossification of distal epiphyses of radius and ulna. This development is found to be as early as one year in males and females for the distal epiphysis of radius, but that of ulna starts to ossify only at 3 years in females and 6 years in males. The latest times by which the distal epiphysis of radius is ossified in Saudi females is 3 years and 4 years in males. However, these ages are later for the distal epiphysis of ulna, which are 8 years in females and 10 years in males.

Shortage of cases in specific age groups, especially the newborns and early infancy period were considered one of the limitations. Owing to the scarcity of normal newborns sent for radiological examination, it was impossible to collect more cases in this group. However, 3 girls and 4 boys gave us an indication of the status of bones at this early age.

As previously mentioned, more cases in phase I of childhood were included in the study because carpal bones are expected to start ossification during this time. The original plan was to examine an approximately equal number of cases in each age group for each phase, but again this was not practical as this depended on the availability of cases for a specific age group.

In general, descriptions in the literature are in accordance with regard to the sequence of appearance of the ossification centers of carpal bones found in this study, that is, the capitate and hamate are the first and the pisiform is the last. There is also an agreement with the order of the other 5 bones: triquetral, lunate, scaphoid, trapezium, and trapezoid. However, a slight difference is observed with regard to the time of appearance of these bones.

The comparison with other studies will be based on the population type. Compared to Indian children, ${ }^{9-11}$ Saudis have a similar pattern of ossification time in terms of the capitate and hamate. However, all other carpal bones, except the pisiform, appear at an earlier time in Saudi children. The pisiform in Saudi males has a similar starting appearance time as in Indians but may not appear until the 14 th year of age in Saudis, whereas this bone is ossified in Indians by 12 years. The pisiform bone in Saudi females starts to ossify at 7 years, which is earlier than the pisiform in Indian females, where this bone starts to ossify only at 10 years. With regard to Pakistani children, the Saudis showed a later time of appearance of capitate and hamate, which occur at the age of one month in the Pakistanis. ${ }^{12}$ However, the other bones develop at an earlier time in the Saudis. The results of this study are comparable to those described in American studies, though the capitate and hamate appear a bit earlier in Americans. ${ }^{8,18}$ As for the Sudanese, Alsharif et al ${ }^{14}$ conducted a small study that included 26 male and 22 female Sudanese infants and toddlers. They reported ossification of the capitate and hamate as early as 2 months in females and 3 months in males. ${ }^{14}$ This finding indicates that these 2 bones arise at a later age in Saudi children, though the small sample size in the present study may not be enough to provide a correct conclusion.

The sequence of appearance of bones described in this study is also in accordance with that generally described in anatomy textbooks or by specific studies on different populations. This study showed that the ossification of these bones occurs earlier in females than in males. However, the difference between males and females was significant only for the pisiform. This difference was also documented in American, ${ }^{8,18}$ Pakistani, ${ }^{12}$ Western Australian, ${ }^{15}$ Indian, ${ }^{9-11}$ Sudanese, ${ }^{14}$ and Argentinian ${ }^{19}$ children.

An important further step that the current study formed a basis for, is to check whether skeletal age of Saudi children matches the chronological age. Skeletal age is a term used to describe the state of maturation of bones as seen in radiographs. ${ }^{20}$ Researchers used several methods to analyze the skeletal age of individuals. The most popular method by Greulich and Pyle (G\&P) uses the atlas. ${ }^{6}$ Another method is Tanner and Whitehouse method, which depends on a scoring technique and needs a trained observer. ${ }^{21}$ More recently, digital methods (computer-aided-diagnosis methods) have been reported to estimate the skeletal age. ${ }^{21-23}$ Example of these digital methods is the one developed by Cameriere et $\mathrm{al}^{24}$ who described a formula based on the ratio between the area of carpal bones and the total area of carpal bones and distal epiphyses of radius and ulna. ${ }^{6,24-26}$ Estimation of skeletal age using MRI or ultrasonography of hand and wrist has been also reported. ${ }^{27,19}$ The atlas by G\&P contains standard normal radiographs of the left hand of children, and these are presented according to age and gender. Number of studies investigated whether radiographs of children of various populations correlate with those described by G\&P. ${ }^{28-30}$ There were no studies for the Saudi population. Accordingly, pediatricians and radiologists in Saudi Arabia are still using the data 
of American Caucasian population (from G\&P atlas) to estimate the chronological age from hand $\mathrm{x}$-rays. Therefore, it would be more appropriate to have a study that compares Saudi data with those in G\&P atlas.

This study can be used as a reference for determining the skeletal age of the Saudi population. The results can guide and facilitate the assessment of growth disorders due to diseases that affect the growth process as well as influence the management of pediatric orthopedic disorders in the Saudi population.

Study limitations. A potential limitation of this study is that the results may not be generalized to represent all Saudi children. This is because of the relatively small sample size due to the limited number of cases available in the hospital during the period of 2012 to 2020 . Therefore, to represent the skeletal age of the population correctly, a larger study should be conducted involving different hospitals in various cities of the kingdom.

In conclusion, this study documented that carpal bones in Saudi children appear in an orderly manner similar to what is described in the literature, starting with the capitate and hamate and ending with the pisiform. Furthermore, ossification of the distal epiphysis of radius preceded that of ulna. A slight difference with regard to the timing of appearance of the bones between Saudis and other populations was found. As in the other nations, ossification in females occurs before that in males.

Acknowledgment. The authors are grateful to Scribendi (www. scribendi.com) for English language editing.

\section{References}

1. Sadler TW. Langman's Medical Embryology. 14th ed. Philadelphia: Wolters Kluwer/Lippincott Williams \& Wilkins.; 2018. p. 167-169.

2. Drake R, Vogl A, Mitchell A. Gray's Anatomy for Students. 4th ed. Philadelphia (PA): Elsevier; 2019. p. 783-784.

3. Hita-Contreras F, Martínez-Amat A, Ortiz R, Caba O, Alvarez P, Prados JC, et al. Development and morphogenesis of human wrist joint during embryonic and early fetal period. J Anat 2012; 220: 580-590.

4. Kamakar RN. Forensic Medicine and Toxicology. 2nd ed. Oral, Practical \& M.C.Q. Kolkata (India): Academic Publishers; 2007. p. 25-26.

5. Manzoor Mughal A, Hassan N, Ahmed A. Bone age assessment methods: a critical review. PakJ Med Sci 2014; 30: 211-215.

6. De Luca S, Mangiulli T, Merelli V, Conforti F, Velandia Palacio LA, Agostini S, et al. A new formula for assessing skeletal age in growing infants and children by measuring carpals and epiphyses of radio and ulna. J Forensic Leg Med 2016; 39: 109-116.
7. Basmajian JV, CE S. Grant's methods of anatomy, a clinical problem-solving approach. 11th ed. Austell (GA): Lippincott Williams \& Wilkins; 1989.

8. Gilsanz V, Ratib O. Hand Bone Age, A Digital Atlas Of Skeletal Maturity. Verlag Berlin Heidelberg (NY): Springer; 2005.

9. Anita, Anand K, Prabhjot C. Study of carpal bone ossification by using radiological method for age estimation of infant and paediatric group in north Indian population. Int. J. Biomed. Res 2018; 4: 38-40.

10. Srivastav A, Saraswat PK, Agarwal SK, Gupta P. A study of wrist ossification for age estimation in pediatric group in central Rajasthan. JIAFM 2004; 26: 132-135.

11. Sidramappa HS, Hemanth RMN, Kumar AGV, Raju K. Radiological study of hand and wrist in the age groups 1-10 years in persons of North Karnataka. Int J Mod Trends Sci Technol 2014; 11: 320-324.

12. Memon N, Memon M, Junejo A, Memon J. Age determination by employing radiological technique in pediatric age groups. $J$ Liaquat Uni Med Health Sci 2011; 10: 53-58.

13. Udoaka A, Blessing D, C Madueke. Determination of skeletal age in Nigerian children: applicalibility of the Greulich and Pyle Atlas. J Forensic Sci 2016; 1: 13-16.

14. Alsharif MHK, Ali AHA, Elsayed AEA, Elamin AY, Mohamed DA. Radiological estimation of age from hand bone in Sudanese infants and toddlers. Open J Intern Med 2014; 4: 13-21.

15. Maggio A. Age estimation using the hand - wrist: morphological assessment of skeletal development in Western Australia [dissertation]. Crawley (WA): University of Western Australia; 2014.

16. World Medical Association. WMA Declaration of HelsinkiEthical Principles for Medical Research Involving Human Subjects. [Updated 2020. Accessed 2020 August 5]. Available from URL: https://www.wma.net/policies-post/wmadeclaration-of-helsinki-ethical-principles-for-medical-researchinvolving-human-subjects/

17. Sue Black JPJ, Anil Aggrawal. Age estimation in the living individuals. In: Madea B, editor. Wiley Online Library. 2020.

18. Hansman CF. Appearance and fusion of ossification centers in the human skeleton. Am J Roentgenol Radium Ther Nucl Med 1962; 88: 476-82.

19. Daneff $\mathrm{M}$, Casalis $\mathrm{C}$, Bruno $\mathrm{CH}$, Bruno DA. Bone age assessment with conventional ultrasonography in healthy infants from 1 to 24 months of age. Pediatr Radiol 2015; 45: 1007-1015.

20. Subramanian S, Viswanathan VK. Bone Age. In: StatPearls Treasure Island (FL): StatPearls Publishing; 2020.

21. Reynolds MS, MacGregor DM, Alston-Knox CL, Gregory LS. Quantifying the ossification of the carpus in skeletal age estimation: radiographic standards for Australian subadults. Forensic Sci Int 2019; 301: e8-e13.

22. Fieuws S, Willems G, Larsen-Tangmose S, Lynnerup N, Boldsen J, Thevissen P. Obtaining appropriate interval estimates for age when multiple indicators are used: evaluation of an ad-hoc procedure. Int J Legal Med 2016; 130: 489-499.

23. Zhang A, Gertych A, Liu BJ. Automatic bone age assessment for young children from newborn to 7-year-old using carpal bones. Comput Med Imaging Graph 2007; 31: 299-310.

24. Cameriere R, Bestetti F, Velandia Palacio LA, Riccomi G, Skrami E, Parente V, et al. Carpals and epiphyses of radius and ulna as age indicators using longitudinal data: a Bayesian approach. Int J Legal Med 2019; 133: 197-204. 
25. Somkantha K, Theera-Umpon N, Auephanwiriyakul S. Bone age assessment in young children using automatic carpal bone feature extraction and support vector regression. J Digit Imaging 2011; 24: 1044-1058.

26. Hsieh CW, Jong TL, Chou YH, Tiu CM. Computerized geometric features of carpal bone for bone age estimation. Chin Med J (Engl) 2007; 120: 767-770.

27. Tomei E, Sartori A, Nissman D, Al Ansari N, Battisti S, Rubini A, et al. Value of MRI of the hand and the wrist in evaluation of bone age: preliminary results. J Magn Reson Imaging 2014; 39: 1198-1205.
28. Hackman L, Black S. The reliability of the Greulich and Pyle atlas when applied to a modern Scottish population. J Forensic Sci 2013; 58: 114-119.

29. Santos C, Ferreira M, Alves FC, Cunha E. Comparative study of Greulich and Pyle atlas and Maturos 4.0 program for age estimation in a Portuguese sample. Forensic Sci Int 2011; 212: 276.e1-e7.

30. Mohammed RB, Rao DS, Goud AS, Sailaja S, Thetay AA, Gopalakrishnan M. Is Greulich and Pyle standards of skeletal maturation applicable for age estimation in South Indian Andhra children? J Pharm Bioallied Sci 2015; 7: 218-225.

\section{Authorship entitlement}

Excerpts from the Uniform Requirements for Manuscripts Submitted to Biomedical Journals updated November 2003.

Available from www.icmje.org

The international Committee of Medical Journal Editors has recommended the following criteria for authorship; these criteria are still appropriate for those journals that distinguish authors from other contributors.

Authorship credit should be based on 1) substantial contributions to conception and design, or acquisition of data, or analysis and interpretation of data; 2) intellectual content; and 3) final approval of the version to be published. Authors should meet conditions 1,2 , and 3 .

Acquisition of funding, collection of data, or general supervision of the research group, alone, does not justify authorship.

An author should be prepared to explain the order in which authors are listed. 